\title{
Dorsalization of the neural tube by the non-neural ectoderm
}

\author{
Mary E. Dickinson ${ }^{1}$, Mark A. J. Selleck ${ }^{2}$, Andrew P. McMahon ${ }^{1, *}$ and Marianne Bronner-Fraser, ${ }^{2, *}$ \\ ${ }^{1}$ Department of Molecular and Cellular Biology, Harvard University, 16 Divinity Ave., Cambridge, MA 02138, USA \\ ${ }^{2}$ Developmental Biology Center, University of California, Irvine, CA 92717, USA \\ *Authors for correspondence
}

\section{SUMMARY}

The patterning of cell types along the dorsoventral axis of the spinal cord requires a complex set of inductive signals. While the chordamesoderm is a well-known source of ventralizing signals, relatively little is known about the cues that induce dorsal cell types, including neural crest. Here, we demonstrate that juxtaposition of the non-neural and neural ectoderm is sufficient to induce the expression of dorsal markers, Wnt-1, Wnt-3a and Slug, as well as the formation of neural crest cells. In addition, the competence of neural plate to express Wnt-1 and Wnt-3a appears to be stage dependent, occurring only when neural tissue is taken from stage 8-10 embryos but not from stage 4 embryos, regardless of the age of the non-neural ectoderm. In contrast to the induction of Wnt gene expression, neural crest cell formation and Slug expression can be induced when either stage 4 or stage 8-10 neural plates are placed in contact with the non-neural ectoderm. These data suggest that the non-neural ectoderm provides a signal (or signals) that specifies dorsal cell types within the neural tube, and that the response is dependent on the competence of the neural tissue.

Key words: neural crest, spinal cord, Wnt genes, pattern formation, induction, cell signaling, chick embryo

\section{INTRODUCTION}

The vertebrate central nervous system (CNS) is patterned through a series of inductive events. Signals thought to derive from the dorsal mesoderm induce neuroectoderm, making it distinct from adjacent non-neural ectoderm (reviewed by Harland, 1994). Soon after neural induction and concomitant with the first morphological appearance of the neural plate, patterning becomes evident along the rostrocaudal axis. This process is likely to involve cues that influence adjacent tissue within the plane of the epithelium (planar signals) as well as signals derived from the underlying mesoderm (vertical signals) (see Doniach, 1993 for review). A third set of signals contributes to cell type diversity along the dorsoventral axis. The notochord is well-known to be important in establishing dorsoventral polarity within the spinal cord (reviewed by Jessell and Dodd, 1993; Smith, 1994). Notochord-derived signals can induce the formation of ventral structures (i.e., floor plate and motor neurons) (van Straaten et al., 1985a, 1985b, 1988; Smith and Schoenwolf, 1989; Placzek et al., 1990; Yamada et al., 1991; Artinger and Bronner-Fraser, 1992; Placzek et al., 1993; Yamada et al., 1993) and can repress or prevent the expression of dorsal markers (Yamada et al., 1991; Basler et al., 1993; Goulding et al., 1993). Moreover, ventral structures are absent and dorsal gene expression is expanded if the notochord is removed at early stages (Yamada et al., 1991; Basler et al., 1993; Goulding et al., 1993). Thus, signals derived from the notochord appear to be both necessary and sufficient for the formation of ventral cell types within the spinal cord.

While a great deal is known about the ventral signals that pattern the spinal cord, very little is known about the inductive events necessary for the formation of dorsal cell types. It is possible that the formation of dorsal cell types may represent a default state; thus, inductive events may only be required to repress the formation of dorsal cell types in ventral regions. Alternatively, dorsalization may require signals from adjacent tissues, similar to the requirement of the notochord to form ventral structures. Two lines of evidence have led us to investigate the possibility that the non-neural ectoderm is the source of a dorsalizing signal. First, it has been shown that interactions between non-neural ectoderm and neural plate tissue can induce the formation of neural crest cells, which normally form only from dorsal regions of the neural tube (Moury and Jacobson, 1989, 1990; Selleck and Bronner-Fraser, 1995). Second, Wnt-1, which is normally expressed only in the dorsal spinal cord, is induced ventrally when contact is made with the overlying surface ectoderm in a mouse mutant that lacks somites (Takada et al., 1994).

In this study, we have used tissue recombination experiments in chick embryos to determine whether interactions between the neural and non-neural ectoderm are sufficient to induce the expression of dorsal markers. Our data indicate that interactions between the neural and non-neural ectoderm can induce dorsal markers as well as neural crest cells depending upon the state of competence of the neural tissue.

\section{MATERIALS AND METHODS}

\section{Isolation of tissues for in vitro culture and grafting experiments}

Fertile chicken eggs (White leghorn) were incubated for 18-24 hours 
to obtain stage 4 embryos and 28-36 hours to obtain stage 8-10 embryos (Hamburger and Hamilton, 1951). Stage 4 presumptive neural plate explants were isolated from the region of the embryo just rostral to Hensen's node (approximately $100 \mu \mathrm{m}$ squares). Stage 4 embryos were placed in a solution of either $1 \mathrm{mg} / \mathrm{ml}$ Dispase (Boehringer Mannheim) or in $\mathrm{Ca}^{2+} / \mathrm{Mg}^{2+}$-free PBS to aid in the dissection and ensure all tissue was free from mesodermal and endodermal cell contamination. Intermediate neural plate explants were taken from stage 8-10 donor embryos; explants included approximately the ventral half of the caudal neural plate excluding the floor plate; on average explants were approximately $80 \times 50 \mu \mathrm{m}$ in dimension. Neural plates from stage 8-10 embryos were dissected in the presence of 1 $\mathrm{mg} / \mathrm{ml}$ Dispase (Boehringer Mannheim). Ventral grafts, with or without the notochord, were isolated in a similar way and included the ventral-most third of the open neural plate. All neural explants, regardless of donor stage or treatment, were rinsed twice with $\mathrm{Ca}^{2+} / \mathrm{Mg}^{2+}$-free PBS and then were allowed to recover in $10 \%$ horse serum in F-12 media (Gibco-BRL) for 20 minutes to 2 hours on ice prior to grafting or embedding in collagen gels. Approximately 200 $\mu \mathrm{m}$ square pieces of presumptive non-neural ectoderm were dissected from a region near the area pellucida/area opaca border of either stage 4 or stage $8-10$ embryos in the presence of ice-cold $\mathrm{Ca}^{2+} / \mathrm{Mg}^{2+}$-free PBS. Recombinants were made by wrapping the recovered neural plates in the non-neural ectoderm directly after it was dissected. Recombinants were then placed in F-12 media (Gibco-BRL) which was warmed to $38^{\circ} \mathrm{C}$ so that the tissues would adhere to one another. Both recombinants and isolated pieces of non-neural ectoderm alone were then kept at room temperature for approximately 20 minutes to 1 hour in $10 \%$ horse serum in F-12 before embedding in collagen gels.

\section{In vitro growth of explanted tissues}

Collagen matrix gels were prepared as previously described (TessierLavigne et al., 1987; Artinger and Bronner-Fraser, 1993), except that commercially produced collagen was used (Collaborative Research) and only $10 \mu \mathrm{l}$ of bottom collagen and 3-5 $\mu \mathrm{l}$ of top collagen was used to ensure efficient penetration of digoxigenin-labeled probes in subsequent whole-mount in situ hybridization steps. Cultures were grown in $\mathrm{F}-12$ media plus N-2 supplements (Gibco-BRL) at $38^{\circ} \mathrm{C}, 5 \% \mathrm{CO}_{2}$ for 24 or 48 hours.

\section{Neural tissue grafts}

Eggs and embryos were prepared for in ovo manipulations using standard methods (see Artinger and Bronner-Fraser, 1992). Neural plate tissues were grafted into stage 8-20 host embryos by gently peeling up a small region of the non-neural ectoderm creating a pocket in which the donor tissue could be inserted. Eggs were sealed with adhesive tape and incubated for 24 hours in a forced draft, humid $38^{\circ} \mathrm{C}$ incubator. When stage 4 hosts were used, embryos were grown in modified New culture as described elsewhere (New, 1955; Stern and Ireland, 1981; Selleck and Bronner-Fraser, 1995). Neural plate grafts were placed between the epiblast and hypoblast by making a small incision in the hypoblast (from the ventral side) and inserting the donor tissue between the two layers. All dissections were done either with sharpened tungsten needles or pulled glass capillary pipettes.

\section{Whole-mount in situ hybridization and HNK-1 immunostaining}

Embryos or collagen gels were fixed 4 hours to overnight in $4 \%$ paraformaldehyde and whole-mount digoxigenin in situ hybridization was performed according to the procedures of Wilkinson (1992) except that RNase treatment was omitted. The chick Wnt-1 probe is a $400 \mathrm{bp}$ PCR fragment corresponding to the $5^{\prime}$ region of the gene (Hollyday et al., 1995). A 400 bp PCR fragment corresponding to the $3^{\prime}$ end of the gene was used to detect Wnt-3a transcripts (Hollyday et al., 1995) The $1.6 \mathrm{~kb}$ Sonic hedgehog (Shh) probe has been described in Riddle et al. (1993) and the Slug probe (360 bp) has been described in Nieto et al. (1994). For HNK-1 immunostaining, embryos and collagen gels were fixed in $4 \%$ paraformaldehyde for 4 hours or overnight and then processed immediately for staining according to Selleck and Stern (1992).

\section{Photography}

Following whole-mount in situ hybridization and immunostaining, samples were postfixed in $4 \%$ paraformaldehyde, $0.2 \%$ glutaraldehyde and photographed using an Olympus SZH10 photomicroscope and Kodak Ektachrome 64T film. All of the embryos were photographed using bright-field illumination, whereas photographs of the collagen gels were taken using dark-field illumination. Slides were then scanned into a Macintosh computer using a Kodak RFS 2035 film scanner and composite figures were made using the Adobe Photoshop (Adobe Systems, Inc.) and Canvas (Denaba Software) graphics packages. Final figures were printed on a Tektronics Phaser IISDX printer.

\section{RESULTS}

We have used a combination of in vitro and in vivo approaches to determine if contact between neural tissue and the nonneural ectoderm can induce the expression of dorsally localized gene markers in addition to neural crest. We have used two members of the Wnt gene family, Wnt-1 and Wnt-3a as dorsal markers of the spinal cord and we have correlated the induction of these markers with the timing of neural crest formation, by examining HNK-1 immunoreactivity and Slug gene expression. Wnt- 1 and $W n t-3 a$ are normally expressed in the dorsal spinal cord following the rostral-to-caudal progression of neural tube closure (Wilkinson et al., 1987; Roelink and Nusse, 1991; Hollyday et al., 1995). Slug encodes a putative zinc-finger transcription factor, which is expressed in individual cells within the dorsal neural tube and in neural crest cells as they emerge from the spinal cord. Expression is lost in cells after extended periods of migration away from the neural tube. As such, Slug expression is the earliest known marker for crest cells and may be necessary for their proper development since crest migration is inhibited in embryos grown in the presence of antisense oligonucleotides specific for Slug mRNA (Nieto et al., 1994). In contrast to Slug, the HNK-1 epitope can be detected on the majority of migrating neural crest cells, even after extensive migration (Tucker et al., 1984).

\section{Non-neural ectoderm is sufficient to induce dorsal markers within stage 8-10 but not stage 4 neural plate explants in vitro}

To ascertain whether non-neural ectoderm is sufficient to dorsalize neural explants in the absence of other embryonic cell types, we cultured neural plate explants in the presence or absence of non-neural ectoderm in defined media within a three-dimensional collagen matrix. For these and subsequent experiments, stage 4 presumptive neural plate donor tissue was dissected from the region just rostral to Hensen's node (Fig 1A), whereas, stage 8-10 neural tissue was isolated from intermediate or ventral regions of the open neural plate (Fig. 1B). These tissues were either grown in isolation or recombined with isolated non-neural ectoderm, dissected from a region near the area pellucida/area opaca border (Fig. 1A,B). Both isochronic and heterochronic recombinants were tested in our assays (see below). Cultures were assayed after 24 or 48 hours. 
Table 1. Collagen gel explant cultures

(A) Stage 4 tissues

\begin{tabular}{|c|c|c|c|c|c|}
\hline & \multicolumn{2}{|c|}{ Wnt-1 } & \multicolumn{2}{|c|}{ Slug } & \multirow{2}{*}{$\begin{array}{c}\text { Migrating } \\
\text { HNK-1 }\end{array}$} \\
\hline & 24 hours & 48 hours & 24 hours & 48 hours & \\
\hline Presumptive neural plate + non-neural ectoderm & $0 / 5$ & $0 / 10$ & 9/9 & $0 / 9$ & $9 / 11$ \\
\hline Presumptive neural plate alone & $0 / 5$ & $0 / 8$ & $0 / 10$ & $0 / 6$ & $0 / 12$ \\
\hline Non-neural ectoderm alone & $0 / 6$ & $0 / 7$ & $0 / 10$ & $0 / 6$ & $0 / 6$ \\
\hline
\end{tabular}

(B) Stage 8-10 tissues

\begin{tabular}{|c|c|c|c|c|c|}
\hline & \multirow{2}{*}{$\begin{array}{c}\text { Wnt-1 } \\
48 \text { hours }\end{array}$} & \multirow{2}{*}{$\begin{array}{c}\text { Wnt-3a } \\
48 \text { hours }\end{array}$} & \multicolumn{2}{|c|}{ Slug } & \multirow{2}{*}{$\begin{array}{c}\text { Migrating } \\
\text { HNK-1 }\end{array}$} \\
\hline & & & 24 hours & 48 hours & \\
\hline Intermediate neural plate + non-neural ectoderm & $22 / 28$ & $13 / 14$ & $11 / 11$ & $0 / 22$ & $8 / 9$ \\
\hline Intermediate neural plate alone & $6 / 48$ & $1 / 20$ & $0 / 12$ & $0 / 28$ & $1 / 12$ \\
\hline Non-neural ectoderm alone & $0 / 21$ & $1 / 12$ & $0 / 8$ & $0 / 12$ & $0 / 6$ \\
\hline
\end{tabular}

In previous experiments, interactions between stage 4 presumptive neural plate and non-neural ectoderm induced the formation of neural crest cells (Selleck and Bronner-Fraser, 1995). In keeping with these results, Slug expression was observed in all recombinants after 24 hours in culture (Fig. 2D; Table 1). No Slug expression was observed in cultures analyzed after 48 hours (data not shown and Table 1), consistent with in vivo observations that neural crest cells in the trunk appear to downregulate Slug transcription as they migrate (Nieto et al., 1994). HNK-1positive cells were observed at high frequency in these cultures and appeared to migrate a limited distance from the recombinants after 48 hours (Fig. 2G; Table 1). However, HNK-1-positive cells induced from stage 4 tissues had a more rounded morphology and appeared to migrate less than those induced from later stage tissues (see below). Thus, early stage recombinants grown in defined media may be missing some factor(s) essential for efficient migration within a collagen matrix. Interestingly, no Wnt-1 or Wnt-3a expression was observed in recombinants of stage 4 prospective neural plate and stage 4 prospective epidermis after 24 or $48 \mathrm{~h}$ (Fig. 2A; Table 1). As expected, neural plate or non-neural ectoderm alone failed to express any markers of dorsal neural tube development (Table 1).

To determine if the induction of Wht gene expression was stage dependent, the experiments described above were repeated using neural plates derived from stage $8-10$ embryos. When intermediate neural plate tissue was explanted and placed in contact with the non-neural
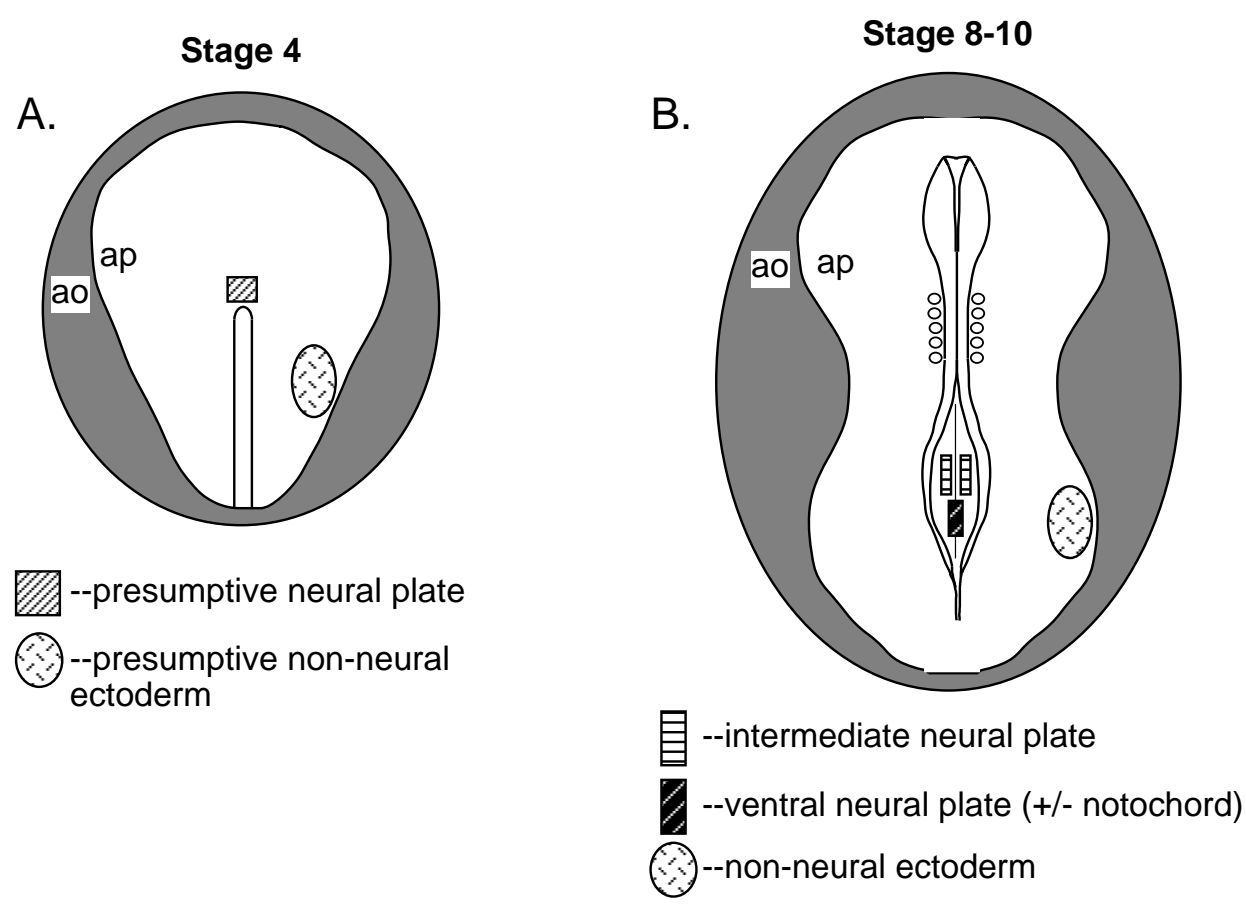

Fig. 1. Diagram representing locations where donor tissues were derived for recombination experiments (see Materials and Methods for more details). Similar tissues were used in experiments described by Selleck and Bronner-Fraser (1995). (A) Presumptive neural plate explants from stage 4 embryos were removed from the region just rostral to Hensen's node (square box), whereas presumptive non-neural ectoderm was removed from a region near the area pellucida (ap)/area opaca (ao) border (area designated by the ellipse). Tissues grafted into stage 4 embryos were typically placed in a region (similar to the one marked by the ellipse) near the area pellucida/area opaca border. (B) Intermediate neural plate explants were removed from the open neural plate of stage 8-10 embryos, with care taken to avoid extreme dorsal, extreme ventral and underlying mesoderm (indicated by the two rectangles on either side of the midline). Ventral neural plate explants contained the ventral third of the open neural plate directly overlying the midline (denoted by the single rectangle) and were either removed from the underlying mesoderm or the notochord was excised with the overlying neural tissue. Non-neural explants consisted of tissue taken from a region near the area pellucida/area opaca border (marked by the ellipse) and grafts of neural plate were placed at several points near the area pellucida/area opaca border, similar to the one marked here, with no difference in the results. 

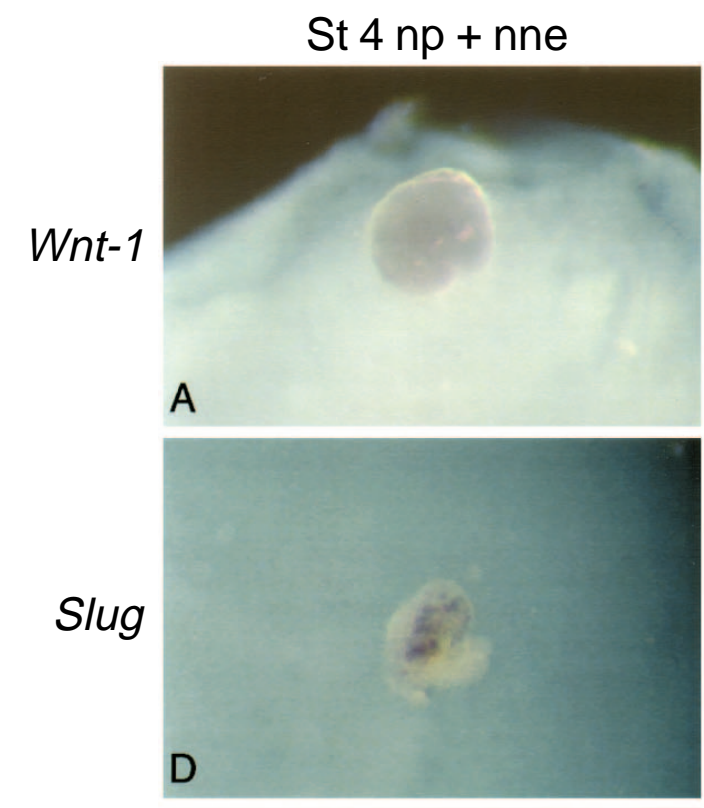

B
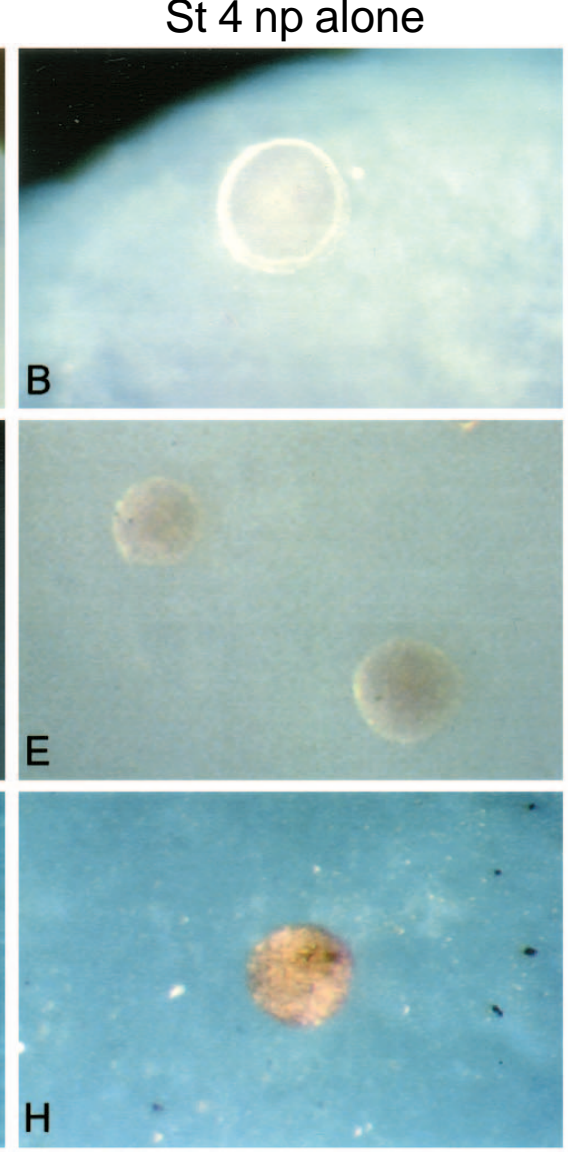
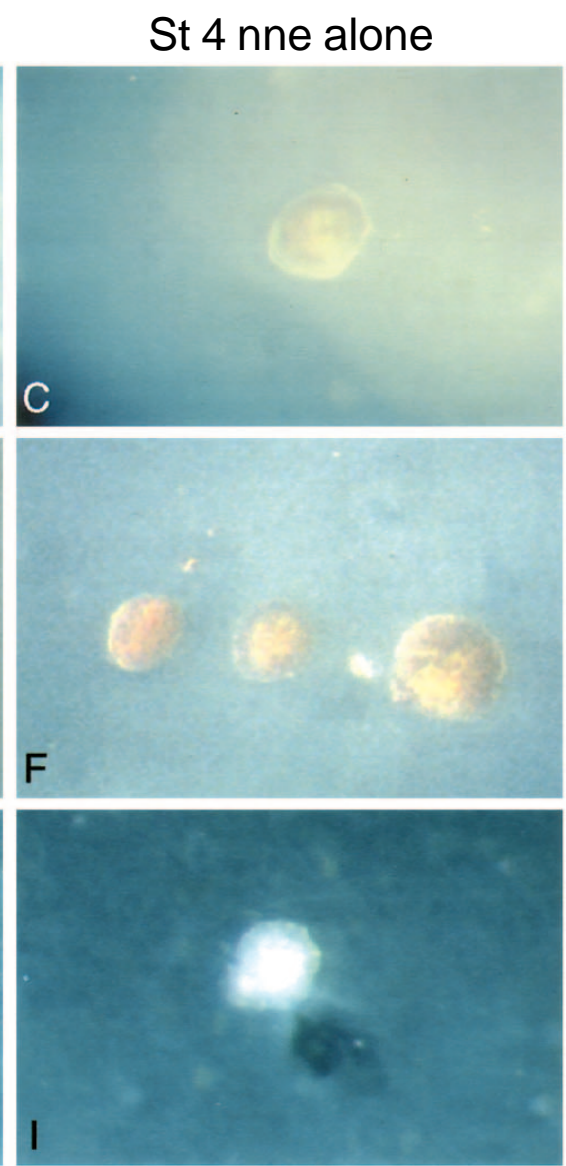

Fig. 2. (A-I) Stage 4 presumptive neural plate (np) and presumptive non-neural ectoderm (nne) tissues grown in defined media within collagen matrix gels and analyzed for the expression of Wnt-1, Slug and HNK-1. (A) Recombinants made from stage 4 neural and non-neural ectoderm, embedded in collagen and grown for $48 \mathrm{~h}$ show no Wnt-1 expression. (B) Neural and (C) non-neural tissues grown alone are also negative for Wnt-1 expression. (D) Recombinants made from these tissues do express Slug after 24 hours in culture, whereas neural plate tissue (E) or presumptive epidermal tissue (F) cultured alone show no Slug expression. (G) Migrating HNK-1-positive cells can be seen after 48 hours surrounding recombinants made with these tissues, showing that neural crest cells are generated and can migrate, at least a limited distance within the collagen matrix. (H) Migrating cells are never seen in these cultures, despite weak staining in the explant itself. (I) Presumptive epidermis cultured alone never shows HNK-1 immunoreactivity.

Table 1), probably due to the inclusion of small amounts of prospective dorsal tissue. Non-neural ectoderm cultured alone never expressed these markers (Table 1). Similar to the results obtained with stage 4 tissues, Slug mRNA was detected in all recombinants after 24 hours (Fig. 3D; Table 1), but in none of the recombinants cultured for 48 hours (data not shown and Table 1). HNK-1 immunoreactive, migrating cells were seen in nearly all recombinants made from tissues at this stage (Fig. 3G; Table 1). These neural crest cells appeared to have a typical 'migratory' morphology, extending numerous filapodia and were often observed several cell diameters away from the initial explant.

In order to determine whether the stage of the neural plate or the stage of the non-neural ectoderm is critical for the induction of Wht gene expression, we made heterochronic recombinants consisting of stage 8-10 non-neural ectoderm and stage 4 presumptive neural plate. Later stage non-neural ectoderm also failed to induce Wnt gene expression in stage 4 presumptive neural tissue (data not shown, Wnt-1,n=0/5), indicating that the stage of the responding neural plate is critical for induction of Wnt gene expression.

\section{Induction of dorsal markers in grafted neural tissues in vivo}

Our in vitro studies indicate that the non-neural ectoderm is sufficient to induce the expression of Wnt-1 and Wnt-3a depending on the stage of the responding neural ectoderm. We were interested in further characterizing this interaction in an in vivo setting to try to answer additional questions about the nature of the dorsalizing signal. For these experiments, we grafted either stage 4 presumptive neural tissue or stage 8-10 intermediate neural plates beneath the non-neural ectoderm at a variety of sites surrounding the embryo within the area pellucida. Host embryos were assayed for all four markers described above 24 hour post-surgery.

In agreement with our in vitro experiments, we found that Wnt-l and Wnt-3a transcripts were not induced in grafted presumptive neural plates from stage 4 donor embryos (Fig. 4A,B and data not shown). However, robust expression of these markers was seen in stage 8-10 neural plate tissues placed beneath the non-neural ectoderm (Fig. 4C,D). We performed these experiments using a variety of host stages and similar to our in vitro data, the induction of Wnt gene expression corre- 
St 8-10 inp + nne

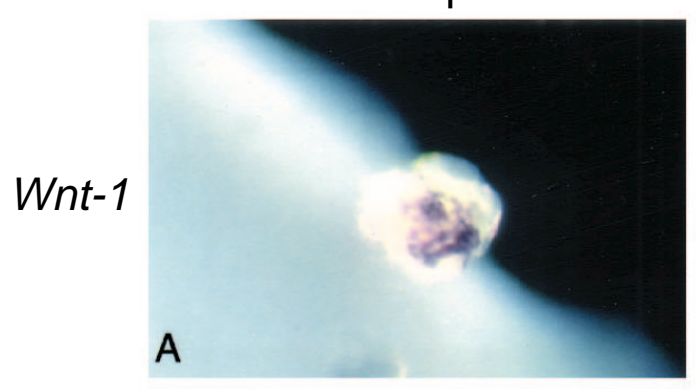

\section{D}

HNK-1

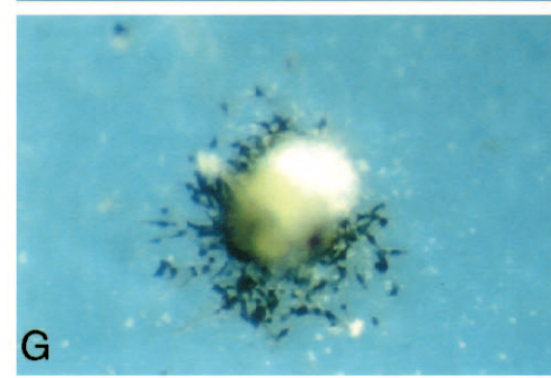

B

St 8-10 inp alone

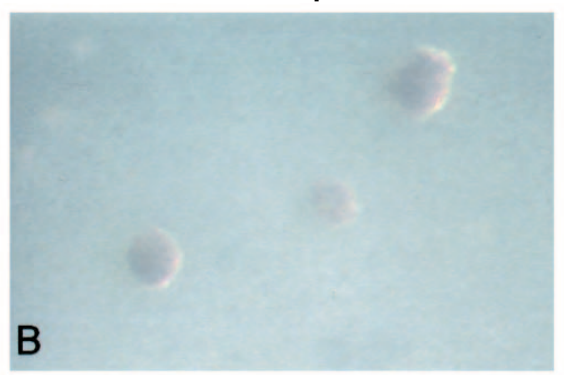

E

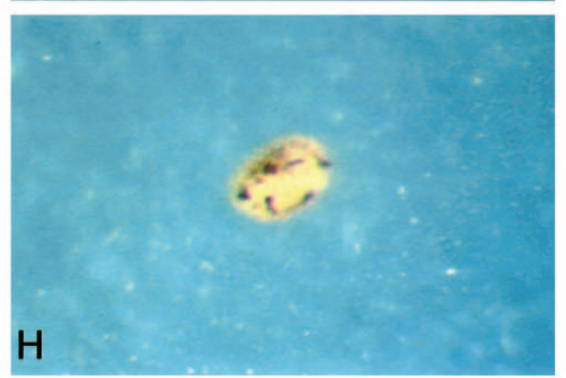

St 8-10 nne alone

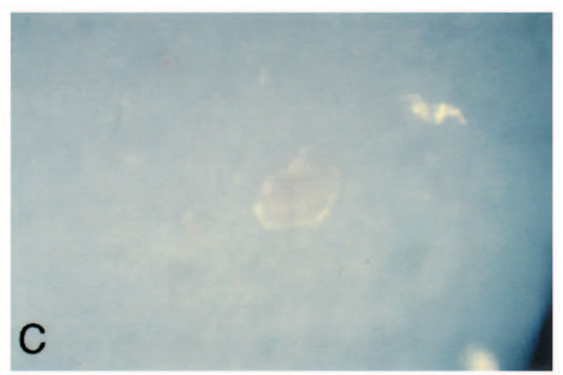

$\mathrm{F}$

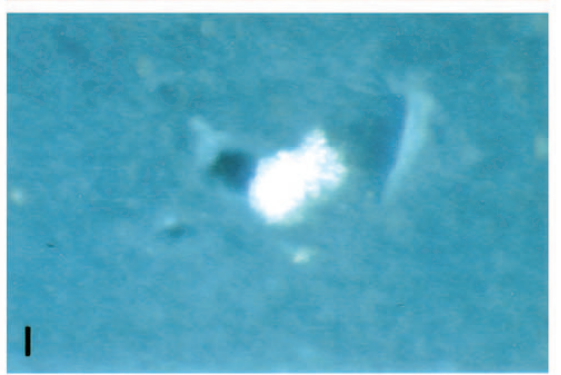

Fig. 3. Stage 8-10 intermediate neural plate and non-neural ectoderm tissues grown in defined media within collagen matrix gels. (A) Wnt-1 expression is seen in recombinants of these tissues grown for 48 hours. (B) Intermediate neural plates alone rarely express Wnt-1 (positive tissue not shown, see Table 2) and (C) non-neural ectoderm cultured alone is always negative for Wnt-1 expression. (D) Slug is also expressed in recombinants made from tissues at these stages after 24 hours, whereas it is never expressed in either the neural (E) or non-neural component (F) after 24 hours. (G) Numerous HNK-1-positive cells are seen migrating from these tissues when they are placed in contact and grown for 48 hours indicating that neural crest cells are induced and have the capacity to migrate within the collagen matrix. (H) HNK-1-positive cells are frequently seen with neural plate explants cultured alone (consistent with its normal expression in the neural tube), but migrating neural crest cells were found in only 1 of 12 recombinants. (I) Explants of non-neural ectoderm never show HNK-1 immunoreactivity when cultured alone for 48 hours.

lates with the stage of the donor neural plate tissue and was independent of the host stage. Stage 4 presumptive neural tissue grafted into either stage 4 or stage 8-10 embryos never expressed Wnt-1 or Wnt-3a, but Slug was induced in these grafts indicating that neural crest cells do form (Fig. 4A,B; Table 2) Wnt-1 and Wnt-3a transcripts were induced if stage 8-10 intermediate neural plate tissue was grafted into stage 810 hosts as well as host embryos as late as stage 20 (Table 2). Interestingly, the position of the grafted tissue did not appear to have an effect on the induction of these markers. Initially grafts were placed randomly around the area pellucida and Wnt-1 /3a expression was detected in all stage 8-10 intermediate neural plate grafts, regardless of graft site (data not shown). This suggests that dorsalizing signals are either not localized within the non-neural ectoderm or that an interaction with neural tissue is necessary to reveal this activity.

Next we wanted to test if ventral neural plate tissue could be induced to express dorsal markers. For these experiments, the ventral third of the open neural plate, including the floor plate, from stage 8-10 embryos was removed, with or without
Table 2. In ovo grafts

\begin{tabular}{|c|c|c|c|c|c|c|}
\hline $\begin{array}{l}\text { Donor } \\
\text { stage }\end{array}$ & $\begin{array}{c}\text { Donor } \\
\text { type }\end{array}$ & $\begin{array}{l}\text { Host } \\
\text { stage }\end{array}$ & Wnt-1 & Wnt-3a & Slug & Shh \\
\hline st. 4 & $\begin{array}{l}\text { Presumptive neural } \\
\text { plate }\end{array}$ & st. $4-10$ & $0 / 9$ & $0 / 4$ & $6 / 6$ & - \\
\hline \multirow[t]{2}{*}{ st. $8-10$} & Intermediate neural & st. $4-10$ & $15 / 15$ & $4 / 4$ & $8 / 8$ & - \\
\hline & plate & st. 20 & $4 / 4$ & - & - & - \\
\hline st. $8-10$ & Ventral neural plate & st. $8-10$ & $7 / 7$ & - & - & $4 / 4$ \\
\hline st. $8-10$ & $\begin{array}{l}\text { Ventral neural plate } \\
+ \text { notochord }\end{array}$ & st. $8-10$ & $8 / 8$ & - & - & $4 / 4$ \\
\hline
\end{tabular}

the notochord attached and was grafted beneath the non-neural ectoderm of stage 8-10 host embryos. Wnt-1 transcripts were induced in ventral neural plates alone as well as in those with the notochord attached (Fig. 4E; Table 2). However, in grafts that contained notochord, a region of the graft corresponding to the prospective floor plate (immediately adjacent to the donor notochord) failed to express Wnt-1. Similar grafts were analyzed for the expression of Sonic hedgehog (Shh) (Riddle et al., 1993; Echelard et al., 1993; Krauss et al., 1993), a factor 
known to induce the formation of ventral cell types within such explants (Roelink et al.,1994). Shh expression was seen in all ventral neural plate grafts even 24 hours after transplantation. In those that contained notochord tissue, the region adjacent to the notochord, which failed to express Wnt-l in identical experiments, expressed $S h h$ as did the notochord itself. Thus, Wnt-1 and Shh appear to be expressed in adjacent but nonoverlapping regions of the same graft. Sections through these embryos confirmed that the entire graft was covered with nonneural ectoderm (data not shown). This result suggests that the ectoderm cannot dorsalize tissue that is in contact with the notochord, but can influence tissue directly adjacent to the floor plate, only a few cell diameters away from the notochord.

\section{DISCUSSION}

Our data demonstrate that interactions between the non-neural and neural ectoderm are sufficient to induce the expression of markers expressed within the dorsal spinal cord as well as neural crest cells. Thus, dorsalization of the spinal cord is likely to result from signals that originate in the adjacent and/or overlying surface ectoderm. These data favor a model in which dorsal cell patterning is the result of an active signaling process rather than a model in which dorsal fates are adopted by default, in the absence of an inductive signal.

The activity that we report does not appear to be localized to any particular region of the non-neural ectoderm. Neural tissue was induced to express the markers that we assayed regardless of the graft site, as long as contact was maintained between the graft and the non-neural ectoderm that overlies the area pellucida. However, it remains possible that contact between the two tissues induces the non-neural ectoderm to express putative dorsalizing factors, which then can act on neural tissue. At this point, it is also unclear whether this activity is freely secreted, matrix-associated or presented on the cell surface. In our in vitro assays, we see only patchy induction of molecular markers indicating that contact or at least very close apposition of the two tissues is necessary (Figs 2D, 3A,D). In addition, it is not known whether there are multiple ectodermderived factors with different functions or if a single factor can induce dorsal marker expression as well as neural crest cells.

In addition to showing that the non-neural ectoderm is sufficient for the induction of dorsal cell types, we have also been able to detect differences in the competence of neural tissue to respond to these dorsalizing signals. Using molecular markers for cells in the dorsal neural tube (Wnt-1 and Wnt-3a) and for neural crest cells (Slug, HNK-1), we have shown that later stage neural explants (stage 8-10) can be induced to express markers of dorsal neural tube and neural crest, but only neural
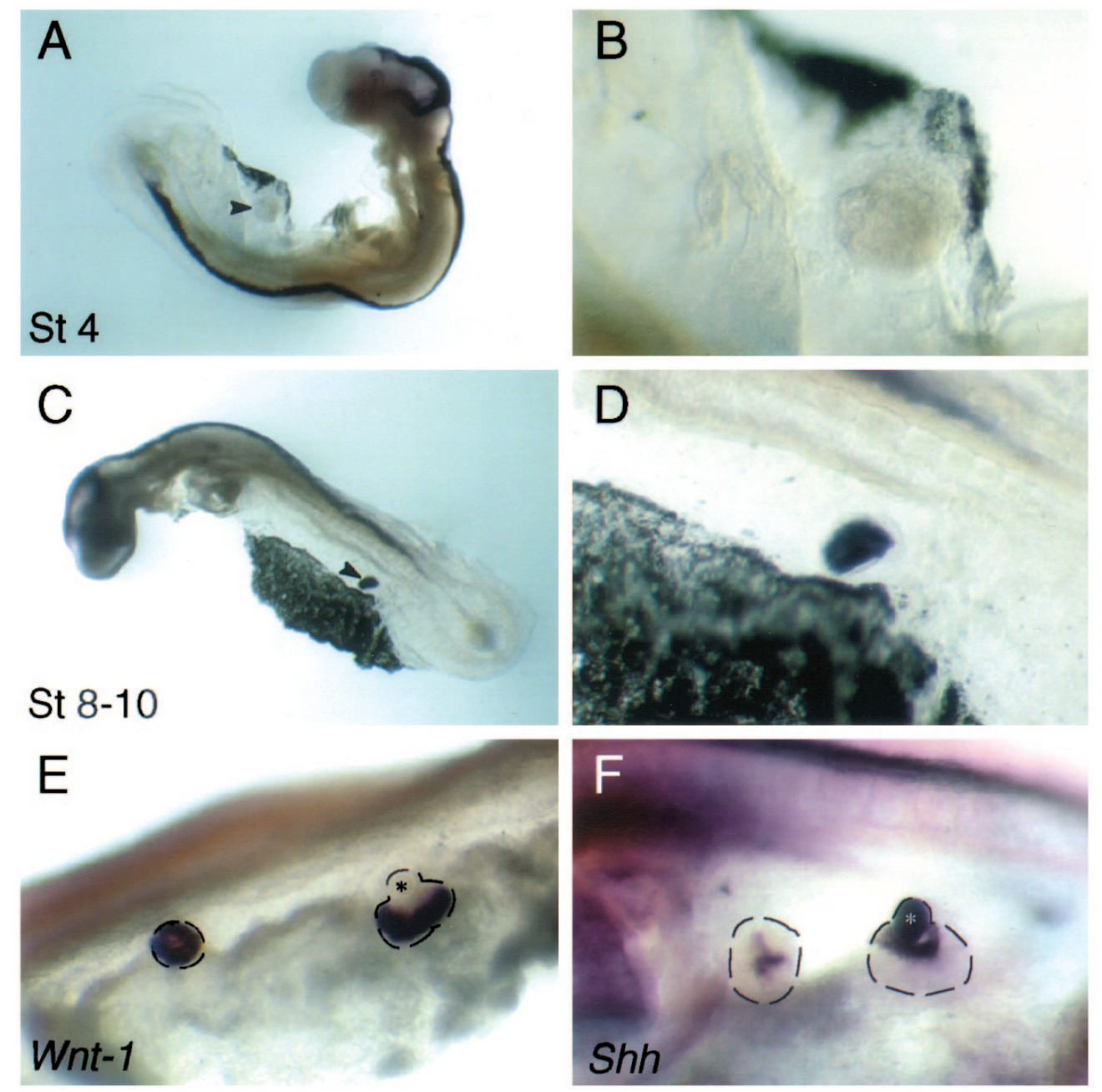

Fig. 4. Wht- 1 and Shh expression in embryos in which an explant of neural tissue (with or without the notochord) has been grafted beneath the non-neural ectoderm near the area pellucida/area opaca border. (A) Presumptive neural plate tissue taken from a stage 4 donor, grafted into a stage 10 host and allowed to grow in ovo for 24 hours before being analyzed for Wnt-1 expression. No expression of Wnt-1 is seen in the graft (arrowhead) despite normal Wnt-1 expression in the rest of the embryo. (B) High magnification of A focusing on the grafted tissue, which lacks Wnt-1 expression. (C) Stage 8-10 intermediate neural plate grafted into a stage 9 embryo and grown for 24 hours. Wnt- 1 is clearly expressed in the grafted tissue (arrowhead, purple stain). (D) High magnification of $\mathrm{C}$ showing high levels of Wnt-1 expression in the graft that lies near the area pellucida/area opaca (stained black) border. (E,F) Ventral neural tissue (graft on the left) and ventral neural tissue plus notochord (graft on the right) were both grafted into stage 9 hosts and then analyzed for either Wnt-l (E) or Shh (F) expression (dotted lines indicate the limits of the grafted tissue and the asterisk marks the notochord). (E) Wnt-1 can clearly be induced in ventral tissue, with the exception of the floor plate region directly in contact with the notochord. (F) Shh expression is maintained for up to 24 hours in the notochord and floor plate in ventral explants grafted into this ectopic site. 
crest cell markers are induced when early stage neural tissue (stage 4) is used. Induction of both sets of markers depends on the stage of the neural tissue and not the stage of the non-neural ectoderm, indicating that the competence of the neural tube to respond to dorsalizing signals changes with time. These data, which compare the induction of different dorsal cell types, confirm and extend those of Selleck and Bronner-Fraser (1995) and provide evidence to support the idea that the induction of neural crest cells may be an earlier event than previously recognized. The differences in the timing of Slug and Wnt-1/3a induction in our experiments mimics events during normal development. Slug expression can be detected within the dorsal neural tube 1-2 hours prior to the onset of Wnt-1 or $3 a$ expression at the same axial level (M. E. D. and A. P. M., unpublished observations), showing that neural crest cell formation precedes the induction of Wnt-1/3a expression, both during normal morphogenesis, as well as in our experimental assays. The early induction of these cells may explain why notochords grafted dorsally repress the expression of many dorsal markers (Yamada et al., 1991; Basler et al., 1993; Goulding et al., 1993), including Wnt-1 and $3 a$ (M. E. D. and A. P. M., unpublished observations), but do not abolish the formation of neural crest cells (Artinger and Bronner-Fraser, 1992). Moreover, we can conclude that Wnt-1 and Wnt-3a are not required for the initial induction of neural crest, since these cells form in the absence of Wnt-1/3a expression.

There is ample evidence that the floor plate and/or notochord play a role in limiting the ventral extent of dorsal gene expression. The notochord can prevent or repress the expression of several dorsally expressed genes (Basler et al., 1993; Goulding et al., 1993), including Wnt-1 and Wnt-3a (M. E. D. and A. P. M., unpublished observations) and the removal of the notochord causes dorsal gene expression to occur in more ventral regions (Basler et al., 1993; Goulding et al., 1993). In this study, we have tested the ability of ventral regions of the neural tube to respond to dorsalizing signals by grafting these tissues beneath the non-neural ectoderm. We show that Wnt- 1 expression can be induced in ventral regions of the neural tube placed in contact with the non-neural ectoderm, even in the presence of the notochord or floor plate. However, Wnt-1 was not induced within the floor plate itself. Thus, it appears that contact between the non-neural and neural ectoderm can overcome long-range repression by the notochord, but cannot influence the tissue in contact with or within a few cell diameters of the notochord. If the activation of these genes is indeed dependent on contact with the surface ectoderm, this may represent another mechanism for restricting expression to dorsal regions.

In addition to its effects on the dorsal neural tube, the nonneural ectoderm appears to have a contact-dependent, dorsalizing influence on mesodermal tissues. Fan and TessierLavigne (1994) have shown that non-neural ectoderm placed in contact with segmental plate mesoderm can induce the expression of genes normally restricted to the dorsal or dermomyotomal compartment of the somite. Our data show that neural dorsalizing signals are present as late as stage 20 (Table 1) and would be included in the inducing ectoderm used by Fan and Tessier-Lavigne (1994). Furthermore, somitic tissue can be ventralized by transplanting a notochord dorsally (Watterson et al., 1954; Pourquié et al., 1993; Brand-Saberi et al., 1993; Goulding et al., 1994) or by supplying Sonic hedgehog protein to these tissues (Fan and Tessier-Lavigne, 1994; Johnson et al., 1994). Therefore, similar or identical signals may be involved in controlling the polarity of both neural and somitic tissues.

Ventralization of the neural tube depends initially on vertical signals from the notochord (reviewed by Jessell and Dodd, 1993; Smith, 1994). This results in the formation of the floor plate, which also has the capacity to induce ventral cell types (Placzek et al., 1991, 1993; Yamada et al., 1991, 1993; Ericson et al., 1992). In a similar way, the non-neural ectoderm may be inducing a 'dorsalizing center' within the neural tube in order to maintain or augment the initial dorsalizing signal(s) derived from the non-neural ectoderm. In support of this hypothesis, the dorsal neural tube secretes a signal that influences the polarity of somitic tissue (Fan and Tessier-Lavigne, 1994) and Dorsalin-1 (Dsl-1), which is expressed in the dorsal spinal cord, can induce neural crest cell migration when added to intermediate neural plate (Basler et al., 1993).

Precise roles for Wnt-1 and Wnt-3a in the development of the dorsal spinal cord have not been elucidated. However, Wnt-I can clearly stimulate the proliferation of precursor cells when ectopically expressed in the mouse spinal cord (Dickinson et al., 1994). Thus, Wnt factors may play a role in the development of dorsal cell types by regulating cell division in precursor cells. By examining the expression of molecular markers in the assays described here, we have begun to dissect different aspects of dorsal induction. Future experiments are aimed at better defining the relationship of Wnt factors, and other molecules, to the events that control cell fate decisions.

We would like to thank Angela Nieto for generously providing the Slug probe and helpful comments, Kristin Artinger for help with collagen gel culture techniques, Margaret Baron, Laura Burrus, Hélène Dassule, Brigid Hogan and Karen Symes for critical reading of the manuscript, Olivia Kelly for stimulating discussions and the anonymous reviewers for improving the manuscript. This work was supported by grants to A. P. M. and M. B. F. (USPHS HD-25138) from NIH. M. E. D. is a graduate fellow supported jointly by Columbia University and the Roche Insitute of Molecular Biology. M. A. J. S. is supported by a fellowship from the Muscular Dystrophy Association.

\section{REFERENCES}

Artinger, K. and Bronner-Fraser, M. (1993). Delayed formation of the floor plate after ablation of the avian notochord. Neuron 11, 1147-1161.

Artinger, K. B. and Bronner-Fraser, M. (1992). Partial restriction in the developmental potential of late emigrating avian neural crest cells. Development 116, 877-886.

Basler, K., Edlund, T., Jessell, T. M. and Yamada, T. (1993). Control of cell pattern in the neural tube: regulation of cell differentiation by dorsalin-1, a novel TGF-ß family member. Cell 73, 687-702.

Brand-Saberi, B., Ebensperger, C., Wilting, J., Balling, R. and Christ, B. (1993). The ventralizing effect of the notochord on chick somite differentiation in chick embryos. Anat. Embryol. 188, 239-245.

Dickinson, M. E., Krumlauf, R. and McMahon, A. P. (1994). Evidence for a mitogenic effect of Wnt-1 in the developing mammalian central nervous system. Development 120, 1453-1471.

Doniach, T. (1993). Planar and vertical induction of anteroposterior pattern during the development of the Amphibian central nervous system. $J$. Neurobiol. 24, 1256-1275.

Echelard, Y., Epstein, D. J., St-Jacques, B., Shen, L., Mohler, J., McMahon, J. A. and McMahon, A. P. (1993). Sonic hedgehog, a member of a family of putative signaling molecules is implicated in the regulation of CNS polarity. Cell 75, 1417-1430. 
Ericson, J., Thor, S., Edlund, T., Jessell, T. M. and Yamada, T. (1992). Early stages of motor neuron differentiation revealed by expression of homeobox gene Islet-1. Science 256, 1555-1560.

Fan, C-M. and Tessier-Lavigne, M. (1994). Patterning of mammalian somites by surface ectoderm and notochord: evidence for sclerotome induction by a hedgehog homolog. Cell 79, 1121-1285.

Goulding, M. D., Lumsden, A. and Gruss, P. (1993). Signals from the notochord and floor plate regulate the region-specific expression of two Pax genes in the developing spinal cord. Development 117, 1001-1016.

Goulding, M. D., Lumsden, A. and Paquette, A. J. (1994). Regulation of Pax-3 expression in the dermomyotome and its role in muscle development. Development 110, 589-607.

Hamburger, V. and Hamilton, H. L. (1951). A series of normal stages in the development of the chick. J. Morph. 88, 49-92.

Harland, R. (1994). Neural induction in Xenopus. Curr. Op. Genet. Dev. 4, 543-549.

Hollyday, M., McMahon, J. A. and McMahon, A. P. (1995). Wht expression patterns in the chick embryo nervous system. Mech. Devel. (in press).

Jessell, T. M. and Dodd, J. (1993). Control of neural cell identity and pattern by notochord and floor plate signals. In, Cell-Cell Signaling in Vertebrate Development. (ed. E. J. Robertson, F. R. Maxfield and H. J. Vogel). pp. 139151. San Diego: Academic Press.

Johnson, R. L., Laufer, E., Riddle, R. and Tabin, C. (1994). Ectopic expression of Sonic hedgehog alters dorsal-ventral patterning of the somites. Cell 79, 1165-1173.

Krauss, S., Concordet, J-P. and Ingham, P. W. (1993). A functionally conserved homolog of the Drosophila segment polarity gene hedgehog is expressed in tissues with polarizing activity in zebrafish embryos. Cell 75, 1431-1444.

Moury, J. D. and Jacobson, A. G. (1989). Neural fold formation at newly created boundaries between neural plate and epidermis in the axolotl. Dev. Biol., 133, 44-57.

Moury, J. D. and Jacobson, A. G. (1990). The origins of neural crest in the axolotl. Dev. Biol., 141, 243-253.

New, D. A. T. (1955). A new technique for the cultivation of the chick embryo in vitro. J. Embryol. Exp. Morph., 3, 326-331.

Nieto, M. A, Sargent, M. G., Wilkinson, D. G. and Cooke, J. (1994). Control of cell behavior during vertebrate development by Slug, a zinc finger gene. Science 264, 835-839.

Placzek, M., Jessell, T. M. and Dodd, J. (1993). Induction of floor plate differentiation by contact dependent, homeogenetic signals. Development 117, 205-218.

Placzek, M., Tessier-Lavigne, M., Yamada, T., Jessell, T. M. and Dodd, J. (1990). Mesodermal control of neural cell identity: floor plate induction by the notochord. Science 250, 985-988.

Placzek, M., Yamada, T., Tessier-Lavigne, M., Jessell, T. M. and Dodd, J. (1991). Control of dorsoventral pattern in vertebrate neural development: induction of polarizing properties of the floor plate. Development 2 Supplement, 105-122.

Pourquie, O., Coltey, M., Teillet, M.-A., Ordahl, C. and Le Dourain, N. M. (1993). Control of dorsoventral patterning of somitic derivatives by notochord and floor plate. Proc. Natl. Acad. Sci. USA 90, 5242-5246.

Riddle, R. D., Johnson, R. L., Laufer, E. and Tabin, C. (1993). Sonic hedgehog mediates the polarizing activity of the ZPA. Cell 75, 1501-1416.

Roelink, H. and Nusse, R. (1991). Expression of two members of the Wnt family during mouse development - restricted spatial and temporal patterns in the developing neural tube. Genes Dev. 5, 381-388.
Roelink, H., Augsberger, A., Heemskerk, J., Korzh, V., Norlin, S., Ruiz I Altalba, A., Tanabe, Y., Placzek, M., Edlund, T., Jessell, T. M. and Dodd, J. (1994). Floor plate and motoneuron induction by $v h h-1$, a vertebrate homolog of hedgehog expressed by the notochord. Cell 76, 716-775.

Selleck, M. A. J. and Bronner-Fraser, M. (1995). Origins of the avian neural crest: the role of neural plate-epidermal interactions. Development 121, 525538.

Selleck, M. A. J. and Stern, C. D. (1992). Commitment of mesoderm cells in Hensen's node of the chick embryo to notochord and somite. Development 114, 403-415

Smith, J. C. (1994). Hedgehog, the floor plate and the zone of polarizing activity. Cell 76, 193-196.

Smith, J. L. and Schoenwolf, G. C. (1989). Notochordal induction of cell wedging in the chick neural plate and its role in neural tube formation. J. Exp. Zool. 250, 49-52.

Stern, C. D. and Ireland, G. W. (1981). An integrated experimental study of endoderm formation in avian embryos. Anat. Embryol. 163, 245-263.

Takada, S., Stark, K. L., Shea, M. J., Vassileva, G., McMahon, J. A. and McMahon, A. P. (1994). Wnt-3a regulates somite and tailbud formation in the mouse embryo. Genes Dev. 8, 174-189.

Tessier-Lavigne, M., Placzek, M., Lumsden, A. G. S., Dodd, J. and Jessell, T. M. (1987). Chemotropic guidance of developing axons in the mammalian central nervous system. Nature 336, 775-778.

Tucker, G. C., Aoyama, H., Lipinski, M., Tursz, T. and Thiery, J. P. (1984). Identical reactivity of monoclonal antibodies HNK-1 and NC-1: Conservation in vertebrates on cells derived from the neural primordium and on some leukocytes. Cell Diff. 14, 223-230.

van Straaten, H. W. M., Hekking, J. W. M., Thors, F., Wiertz-Hoessels, E. L. M. and Drukker, J. (1985a). Induction of an additional floor plate in the neural tube. Acta Morphol. Neerl. Scand. 23, 91-97.

van Straaten, H. W. M., Hekking, J. W. M., Wiertz-Hoessels, E. L., Thors, F. and Drukker, J. (1988). Effect of the notochord on the differentiation of a floor plate area in the neural tube of a chick embryo. Anat. Embryol. 177, 317-324.

van Straaten, H. W. M., Thors, F., Wiertz-Hoessels, E. L., Hekking, J. W. M. and Drukker, J. (1985b). Effect of a notochordal implant on the early morphogenesis of the neural tube and neuroblasts: histometrical and histological results. Dev. Biol. 110, 247-254.

Watterson, R. L., Fowler, I. and Fowler, B. J. (1954). The role of the neural tube and notochord in the development of the axial skeleton in the chick. Am. J. Anat. 95, 337-399.

Wilkinson, D. G. (1992). Whole mount in situ hybridization of vertebrate embryos. In In Situ Hybridization: A Practical Approach. (ed. D. G. Wilkinson). pp. 75-83. Oxford: IRL Press.

Wilkinson, D. G., Bailes, J. A. and McMahon, A. P. (1987). Expression of the proto-oncogene int- 1 is restricted to specific neural cells in the developing mouse embryo. Cell 50, 79-88.

Yamada, T., Pfaff, S. L., Edlund, T. and Jessell, T. M. (1993). Control of cell pattern in the neural tube: Motor neuron induction by diffusible factors from notochord and floor plate. Cell 73, 673-686.

Yamada, T., Placzek, M., Tanaka, H., Dodd, J. and Jessell, T. M. (1991). Control of cell pattern in the developing nervous system: Polarizing activity of the floor plate and notochord. Cell 64, 635-647. 